University of Louisville

ThinkIR: The University of Louisville's Institutional Repository

\title{
"What to inspect when you're expecting" : critically examining constructions of women in What to expect when you're expecting.
}

Kirsi Lancaster

University of Louisville

Follow this and additional works at: https://ir.library.louisville.edu/honors

Part of the Feminist, Gender, and Sexuality Studies Commons

\section{Recommended Citation}

Lancaster, Kirsi, "'What to inspect when you're expecting" : critically examining constructions of women in What to expect when you're expecting." (2017). College of Arts \& Sciences Senior Honors Theses. Paper 130.

http://doi.org/10.18297/honors/130

This Senior Honors Thesis is brought to you for free and open access by the College of Arts \& Sciences at ThinkIR: The University of Louisville's Institutional Repository. It has been accepted for inclusion in College of Arts \& Sciences Senior Honors Theses by an authorized administrator of ThinkIR: The University of Louisville's Institutional Repository. This title appears here courtesy of the author, who has retained all other copyrights. For more information, please contact thinkir@louisville.edu. 
"WHAT TO INSPECT WHEN YOU'RE EXPECTING": CRITICALLY EXAMINING CONSTRUCTIONS OF WOMEN IN WHAT TO EXPECT WHEN YOU'RE EXPECTING

\author{
By \\ Kirsi Lancaster \\ Submitted in partial fulfillment of the requirements \\ for Graduation summa cum laude \\ and \\ for Graduation with Honors from the Department of English \\ University of Louisville \\ Undergraduate Honors Thesis
}

March 2017 


\section{“What To Inspect When You're Expecting": Critically Examining Constructions of Women in What To Expect When You're Expecting}

\section{Introduction}

It is no secret that women are "disproportionately medicalized" and oppressed in our culture (Conrad 10). The pregnant woman's body, therefore, is a particularly vulnerable site for oppression, medicalization, and social control, both through culture and in the clinical encounter. The pregnant body is often a site for perpetuating harmful gender norms and is increasingly a site of surveillance (Ayala and Freeman; Sherwin Normalizing). As feminist author and philosopher Renate Duelli Klein remarks, the control of women's reproductive systems in particular, "has been a crucial factor in the oppression of women" (65), and as political scientist Lauren Woliver remarks, the increasing medicalization of women's reproduction has "shift[ed] control from the pregnant woman to doctors... at the expense of the pregnant woman" (30). It is well known that the language used to speak about women's bodies and reproduction is both value-laden and value-producing (Martin; Rothman; Shanner; Campo-Engelstein and Johnson). Thus it is critical that we are aware of how language contributes to and perpetuates these oppressions.

In the following paper I analyze the language used in the most recent edition of the most popular pregnancy manual in the United States, Heidi Murkoff and Sharon Mazel's What to Expect When You're Expecting (WTEWYE) (2016). WTEWYE, first published in 1984 and now in its fifth edition, is a widely-read self-help book written for women as a comprehensive guide to pregnancy, boasting itself as the "\#1 Bestselling Pregnancy Book" and "America's Pregnancy Bible." Despite the popularity of this text, it has not, to my knowledge, received much in the way of scholarly critique, particularly in regards to the most recent edition, since it has so recently been published. In WTEWYE, there is a month-by-month look at the pregnancy, as well as 
information on how to eat "right" during pregnancy, various complications or questions a woman might have about things that could effect her pregnancy, symptoms she might have, tips for navigating pregnancy, descriptions of the various tests that physicians may perform during prenatal appointments as well as a section on pregnancy loss. The text covers the time from conception through the first 6 weeks following postpartum. Since people tend to seek the most up to date medical information, the most recent edition will likely be the most commonly purchased and consumed going forward. Therefore, I am focusing on the language in the most recent edition, published in 2016.

In their article, "Rhetorical Visions of Motherhood," communications professors Catherine Dobris and Kim White-Mills note the "enormous impact" that the What to Expect series has had on how people "rhetorically construct the experience of pregnancy" due to the series' massive popularity (28). Viewing pregnancy within the language of traditional gender norms reinforces ideologies that contribute to existing power dynamics. Deeply embedded gender stereotypes in the What to Expect series, such as the idea that the apex of a woman's life is giving birth, or subtle reminders that women are naturally nurturing, allow the creation and perpetuation of powerful cultural ideologies because the perceptions of how people are expected to behave are not challenged (Dobris and White-Mills 27).

Feminist philosopher Marilyn Frye famously likened oppression to a bird cage in "Oppression and the Use of Definition," explaining that if we look only at one statement or one part of oppression, like one wire of a cage, we fail to see the bigger picture of the many wiresthe structural components of oppression — that prevent us from simply going around the single wire on which we have focused. Much like her conception of oppression, comments reinforcing cultural gender norms work in unison to create a larger picture of an ideal woman. Through 
implicit cultural messages constructing what constitutes "good" womanhood and how it is performed, (i.e., thin, middle class, white, heteronormative, feminine homemaker), women are encouraged to fulfill specific, narrow social roles. These messages are then picked up and internalized by the broad audience of women reading the text and can affect how women view themselves. Although not all women will experience WTEWYE as a text that reinforces oppressive structures, the fundamental veracity of this claim remains intact. As philosophers Ann E. Cudd and Laura Shanner have both separately articulated, and which Cudd captures perfectly, "one can be objectively oppressed and not know it or feel it" (Cudd 23). It is entirely possible to be oppressed and not experience it as such.

In light of the problematic language surrounding women, generally, and pregnancy more specifically, it is important to examine the further cultural implications of language functioning to perpetuate the gender norms which contribute to problematic constructions of women and reproduction. Emily Martin demonstrated in her well-known essay "The Egg and the Sperm" that the use of language in medical texts is influenced by and perpetuates cultural gender norms, demonstrating the problematic relationship between culture, language, and medicine. Similarly, it is important to critically analyze the language used in WTEWYE, especially since it is consumed by such a large number of people.

Since the first edition, the authors attempt to take on a more conversational tone with the reader, positioning themselves as friendly yet knowledgeable and somewhat authoritative sources of information who can be trusted and who are easily relatable. They back their authority up with an introduction from a physician condoning the content of WTEWYE. The authors have also attempted to make the language more value neutral by adding more inclusive language since the first edition. However, in this paper, I argue that the language in WTEWYE is not value 
neutral and as such has harmful implications for how society views and treats women and how women come to view and understand themselves. I draw out the dangerous implications of the language in the text, such as reinforcing patriarchal cultural ideas about women and their bodies, which, then have the potential to manifest themselves as both direct and indirect forms of harm to women. First I look at gender norms and gender essentialism promoted in WTEWYE. Next, I discuss body image and sexualization, class and motherhood, woman as fetal environments, increased surveillance of women's bodies and conception of risk, and finally, the normalization of reproductive technology. I will also remark in the conclusion on potential harms via contributions to rape culture which could potentially occur through dangerous ideological constructions of gender. Some of the harmful implications I discuss are: the impacts on women's self-worth as individuals; the social trend of placing personal responsibility on the woman for any potential risk to her fetus; and unnecessary medical interventions in women's pregnancies. Before I move on to this discussion, however, I must first further develop the context of the language in WTEWYE in the following section.

\section{"For Fathers": Disclaimers and Inclusivity}

Although much of the text of WTEWYE addresses the pregnant woman directly, there are also sections labeled "For Fathers" scattered throughout the newest edition of the text in which the father is directly addressed. In the first edition of WTEWYE a chapter for fathers was included in the back of the book, but by spreading the information throughout, the current text now makes the information more relevant to what the woman is reading and more importantly encourages "the father" to engage more of the book since his information isn't located neatly within a single chapter to which he can quickly jump. Although the authors include a text box in 
the newest edition titled "A Book For All Families" in which they address the fact that not all families fall into strict heteronormative categories, they ask that the woman (and partner, or lack thereof) reading this text simply "mentally edit out" phrases that are not inclusive and "replace it with one that's right for you" (19). While the acknowledgement of the need for inclusive language is a marked improvement from the first edition of the text, there are several problematic ideas that are immediately evident in this claim.

First, the responsibility for inclusivity is removed from the authors and placed onto the pregnant woman reading the text. This move reinforces and plays into existing oppressive power dynamics. As women already occupy a position of lower power in our society, and considering that pregnant women are particularly vulnerable, the fact that women who are not in culturally "normal" relationships are expected to mentally address oppressive, heteronormative language themselves removes the focus from cultural norms and the effects of language and places the focus and the burden on the woman who is already systematically disadvantaged in our culture. Removing responsibility for social problems from the structures that create them to the individual pregnant woman is a recurring theme in both medicalized pregnancy and in healthcare more generally (Richardson et al; Ayala and Freeman; Purdy; Lock; Seigel 101). Thus asking women to ignore non-inclusive language to avoid its effects is not only inconsiderate and harmful, but it fails to address the larger social context and the prevailing structural cultural norms at play.

This request to the pregnant woman also ignores the effects of being constantly inundated with messages, even if the reader subsequently "edits" them out. Further, the request reinforces the social hierarchy of heteronormative relationships by subtly implying that anything differing from the "standard" used throughout the book is a deviation that must be dealt with on the 
reader's own time. This implied standard also suggests that any deviations from the norm are both A) rare enough to not warrant inclusion in the text's language and B) not important enough to inspire updates in the language, even though the authors have clearly had no issue with other major (and minor) edits throughout the years. The authors already made an attempt to use "partner" throughout the text and to refer to others (such as physicians or fetuses) as "he or she." It would have been a simple and important improvement to successfully complete their attempt at inclusive language by referring the woman's partner as "they," and taking out occasional unnecessary phrases indicating that the partner is assumed to be a normative male instead of asking the woman to mentally do it herself. Signaling that the woman may mentally edit the langue as she chooses only gestures at inclusivity and allows further problematic language to slip past since the authors have essentially put a disclaimer on their language.

Similarly, there is another aside in which the authors state that the boxes labeled "For Fathers" scattered throughout the text are really meant for not only fathers but also families with "two mommies" (48) even though the language within these boxes is clearly intended for heteronormative men. For example, there is a box on male changes during a partner's pregnancy, in which his testosterone levels are discussed (222) and a section on how he might address feeling "left out" due to the biological differences of his and her body (481). The text also includes language coded for men through gender norms, such as the reference to "hitting the gym" and "cleaning out the garage" (162), the man's naturally "raging sex drive" (222), and reference to the cultural expectation that men are typically "strong" in times of emotional distress (600). Even the title of the boxes, "For Fathers" rather than the more neutral "For Partners" signals that despite the text's claim to the contrary, these boxes were intended for traditionally male partners of female pregnant women. Therefore, the remainder of this paper will assume that 
these boxes are addressing their specifically intended audiences, despite the attempt at a disclaimer to the contrary offered by the authors.

\section{Tracing Changes}

Although the text reinforces gender norm ideologies in more subtle ways, the newest edition has improved the language used to talk about sex. The very first edition mentions that the woman might have to participate in "obligatory sex" for her husband's satisfaction $(139,140)$. This phrase encourages women to accept and normalize being violated for their spouse's sexual pleasure, as if they are the property of their husbands rather than individual beings. The newest edition has taken a different approach and includes messages to both the woman and the "father" that whether or not they have sex and how they have sex should be left up to the woman and the man should respect her bodily needs, desires, and boundaries. The text also works to normalize any sexual activity (or lack thereof) that the pregnant woman may want to engage in by assuring her that really anything and everything is normal since everyone is different (273). This is a marked improvement form the first edition's reference to "obligatory sex" (140). Although this language has greatly improved the messages they send to women about their sexual lives and sexual autonomy, the authors still have yet to move away from heteronormative relationships as mentioned in the previous section. The authors assume that if the woman is having sex it is with a man who is at least the father of her child, if not her husband.

While other positive changes include a section on domestic violence, at least a recognition of the need for inclusive language (e.g. the switch to "partner"), a section for women without insurance, and a more sex-positive outlook on women's sexuality, there are several negative changes that have occurred from the first edition to the most recent as well. Most 
notable, perhaps, is the complete absence of a section on negotiating the patient-physician relationship in the newest edition. Although the language in the first edition surrounding this discussion was strong in suggesting women stay away from extremes of controlling practitioners with a "godlike aura" or those who merely serve as a "consultant" (23), the ultimate goal was to encourage women to have egalitarian partnerships with their physicians. The authors of the first edition tell women to listen to their own bodies, even, at times, despite what the physician thinks. For example, women are told that if they think they are pregnant, even after the physician says they are not, they should ask for a retest since their bodies sometimes know better than the physician (21). The authors also encouraged women to speak up, counter, and ask questions of their practitioners throughout the first edition of the text. Encouraging women to take an active role in their pregnancies and to consider what kind of patient they are in order to find the best clinical experience for themselves was a positive message that is completely absent in the most recent edition. Instead, in the newest edition, women are given the message that they ought to be completely submissive to the practitioner, who is assumed to always know best, through constant reminders to ask their practitioners about even minor things, like drinking herbal teas, and reminders that the practitioner always has the final say.

While the explosion of accessible medical information in the internet age has challenged the authority of physicians, the medical community has, in several ways, attempted the "reappropriation of patient's short-lived autonomy and of knowledge/power itself" (Kopelson 370) to maintain and reinscribe existing power structures. This shift to "physician knows best" may reflect a trend in medicine towards an attempt to protect and reinstate physicians' position of power in light of anxieties over the loss of medical authority through public access to medical information (Kopelson). Since the 2016 edition includes far more risk factors to be aware of than 
the 1984 edition, there is also a heightened sense of anxiety, risk, and personal responsibility in the newest edition, as I will discuss in more detail later.

While the wealth of medical knowledge can serve to inform and empower the pregnant woman, there is also an increasing expectation that she is now completely individually responsible for the health outcomes of both her fetus and herself, as demonstrated with subtle reminders in WTEWYE that "as much as obstetrical science can do to help you have a safe pregnancy and a healthy baby, it's nothing compared to what you can do yourself' (emphasis added, 48). Although the physician knows best, the pregnant woman is expected to take full responsibility for outcomes. When taken as a whole, the competing messages of personal responsibility for health and submission to medical authorities function to keep the pregnant woman under surveillance by both herself and the medical practice, while removing any potential blame or responsibility from social issues and the medical establishment. Medical sociologist Peter Conrad writes of the cultural phenomenon of medicalization, which he argues "increases the amount of medical social control over human behavior" (8). Between increasingly medicalized bodies and the expectation that patients are responsible for their own health, these paradoxes only continue to work to strengthen medical authority and maintain the physician's position of power in our culture.

The language we use and consume effects and is affected by our culture. Heidi Murkoff and Sharon Mazel, authors of WTEWYE (2016) were likely not setting out to write with the intention of reinforcing harmful ideologies. In fact, it is a function of ideology to ensure that the messages seem to be "simply how things are naturally" (Rothman 32). However, while the authors have, in some ways, improved the language, there is still problematic language throughout the text which reinforces problematic gender and medical ideologies and contributes 
to a general culture of violence against women. In the following discussion, I analyze the most current version of WTEWYE and demonstrate the harmful language it contains. In order to demonstrate the problematic language in the text, I will specifically address the use of gendered stereotypes and norms and the dangers inherent in them, the use of language that encourages thinking about women's bodies as machines, the personification of the fetus, the individualization of maternal responsibility for social risks, and language that encourages increased surveillance of women's pregnant bodies.

\section{Gender Norms}

The gender norms existing in our culture, and which are reinforced in WTEWYE, are "norms relating to domination, over-sexualization, violation, and power and control over women and girls" (Breger 3). Since these norms are embedded deeply in our culture, they can appear "natural," allowing their largely unquestioned and insidious perpetuation in what might otherwise seem to be an unassuming cultural staple like WTEWYE. Themes that reinforce cultural gender norms operate in such a way as to appear natural and obvious in order to ensure their reproduction. For ideology to be successful, our culture must participate in the perpetuation of the ideology, taking for granted the naturalness of it, and personally adopting the ideological ideas as one's own so that they are repeated, internalized, and largely unquestioned (see Althusser). The application of these "obviousnesses as obviousnesses" (Althusser 172) under the ideological system to which our culture adheres is demonstrated in the perpetuation of gender roles and gender norms in a text so widely and uncritically consumed as WTEWYE. Gender norms are oppressive and restrictive to women and, as Frye notes, these restrictions are "internalized and self-monitored" (14). These restrictive gender norms are both replicated and 
promoted in the text because of the complete normalization and internalization by both the authors and the surrounding culture, making these norms appear matter of fact and ordinary.

From the very first page, WTEWYE begins working on subtly implementing these harmful gender norms. The authors associate women with traditionally feminine roles of homemaking by suggesting that the pregnant woman might be aware that "something's cooking" and referring to the fetus as a "bun in your oven" (2). This popular metaphor not only functions to reinforce gender roles for women, but also perpetuates the idea that women's bodies are machines or containers, the purpose of which is to produce children. The woman here seems to have symbolically transcended her traditional role as homemaker to become one of the domestic objects she is expected to use - an oven.

While they acknowledge that the women reading WTEWYE may very well have careers beyond the home, the authors nonetheless continue to replicate the stereotyped gender role idea that women are inherently responsible for the house chores regardless of any potential career they may have. Women with multiple children are told to try to relax in spite of "the getting-toschool or the getting-dinner-on-the-table rush," told to try "napping instead of vacuuming" (27), and are advised to take "advantage of help whenever it's available" implying that childcare and homemaking properly belong to the mother (emphasis added, 27). The authors further tell the pregnant woman that "getting enough rest is more important than keeping your house spotless or cooking 4-star dinners," that she may want to order her groceries online, and give tips on how to take care of and entertain other children at home (130-1). Since the text assumes throughout that the woman has a male partner, presumably her husband, these suggestions continue to reinforce existing gender dynamics and the patriarchal idea that homemaking properly belongs to women. 
Continuing to promote sexist ideas, the text has a section on the safety of various beauty regimens and spa treatments. The section includes advice on things like hair treatments, eyelash treatments, massages, teeth whitening, tanning, and antiwrinkle treatments among others. Beyond a few "pregnancy-appropriate and practitioner approved" exercises in the book (Murkoff and Mazel 44), a comparable section on things that don't involve a woman's appearance, such as working in a garage or workshop, outdoor activities and sports, or artistic endeavors, is noticeably absent, despite the fact that all of these acivities can be just as relaxing and beneficial and involve just as many, if not more harmful chemicals or exertions on the body. Since the text consistently maintains gender norms, it was likely that it was assumed that such a section was not necessary, as these are traditionally "masculine" pursuits. Even if one were to argue that the reason for this is that many women do not do these more "masculine" things and therefore, such a section could be reasonably be skipped, the argument could be flipped since many women also do not participate in these beauty rituals either due to expense, lack of interest in them, concern for her own well-being (as opposed to concern for how these regimens affect the fetus) or a whole range of other reasons women might have for not participating. Noticeably, the safety of these chemicals is not discussed in terms of how they might affect the woman, but rather in terms of the negligible, often theoretical risk that these chemicals could potentially pose to the fetus. The intense level of surveillance a woman is expected to have for these and other aspects of her daily life will be addressed further in a later section.

In addition to gender norms, stereotypes about gender can be harmful as well. For example, the stereotype that women are bad at math prioritizes addressing a boy's difficulty with math over a girl's, if she is considered simply naturally worse at math. The stereotype discourages some women from pursuing math and science fields, and thus they miss out on 
potentially fulfilling careers (Keifer and Sekaquaptewa). Attempting to sound conversational, the authors of WTEWYE reinforce this stereotype when trying to describe a straightforward due date calculation. Due date calculations are calculated as 40 weeks from the first day of her last (most recent) menstrual period. However, this is just an estimate since bodies do not operate on hard and fast deadlines, so the actual delivery could be anywhere +/- 2 weeks from the estimated date. For this reason, the date is called the EDD (Estimated Due Date) (Murkoff 8). The authors of WTEWYE, however, assume that the woman is "already confused" after explaining that the due date is just an estimate for the average pregnancy (8). They continue to assume that their reader is baffled, prefacing the actual calculation with, "here's where things get even more confusing" before proceeding to explain how her due date is calculated. For good measure, the authors finish this section off with "still confused by the system? That's not surprising —it's a confusing system" and reassure women that "happily you don't have to understand the system" (9). This point, resting on the assumption that women are incapable of doing simple calculations, is not only offensive to women, but dangerous since it reinforces the very stereotype on which this assumption relies.

If it is assumed that the average woman reading this text cannot perform even these simple calculations without being entirely lost, then we must grant that on some level, this assumption maintains the common stereotype that STEM fields and intellectual pursuits are naturally masculine, therefore relegating women to the role of caretakers and emotional laborers. This dichotomy, with remnants still alive in our educational culture today, was established to ensure that women remained in the home and presumably out of the way, doing substantial amounts of valuable labor for free. Moreover, statements like this in the text urge women to take a back seat in their own pregnancies and simply follow the direction and supervision of someone 
who can actually understand this "confusing" stuff, namely the physician. Not only is this assumption insulting to women, but it is also patronizing, infantilizing, and rests on the sexist assumption that the average woman is bewildered at even the slightest indication of numbers. Rather than empowering women, the authors set up the expectation that women will not be able to understand the information from the start. The woman is therefore placed in a position in which she is expected to rely on her practitioner, which is problematic insofar as these expectations replicate a power dynamic that has not traditionally been in the best interest of women. This issue will be addressed in more detail later.

\section{Gender Norms for Dad}

Dangerous ideologies concerning gender norms are not only reinforced through the language to the expectant woman, but the "father" is also encouraged in this pervasive line of thinking through the boxes added just for him. While the understanding of social hierarchy based on gender could be harmfully internalized in women, it could be even more dangerous when encouraging this way of thinking in men, since they already hold a position of dominance in our culture. Women, as the subordinate group in this dynamic, have less power in their position from which to effect structural changes, and so encouraging men to replicate and maintain these systems of oppression is incredibly troubling.

One of the boxes "For Fathers" includes information on a "push present" (a gift to the mother for delivering the baby) (383). Under the listed ideas, the authors suggest a "month's worth of professional housekeeping," among other ideas like a facial, flowers, or jewelry (383). Not only are these gifts all traditionally "feminine" things (as opposed to something like new tools or books), but the suggestion that hiring a housecleaner would be a gift to the mother 
implies that the housekeeping was solely her task to begin with. This is even more pronounced when considering that the woman is acknowledged to have a career, implying that she has been stuck with the Second Shift. That he would hire out housework (typically performed by women) rather than taking on the chores himself further suggests that housework is not only the woman's role, but that as the man of the house, he should not have to do the "woman's" job.

On the occasion that it is suggested that he help with some of the home chores, he is praised for going "the extra yard" by stepping out of his traditional role (presumably of the breadwinner) to do things like laundry, dishes, and grocery shopping (172). Dobris and WhiteMills note that while men who help even minimally are depicted as "virtual heroes," women, on the other hand, are not recognized or praised "for doing the jobs they are expected to perform" (33). Praising men for doing the work that women are naturally expected to do reinforces the concept of housework as a role that is not natural for him, constituting a reason for praise and admiration while and continuing to naturalize the conception that women are inherently homemakers.

Even if we grant that this dynamic of working man/stay-at-home woman can be a legitimate and egalitarian relationship dynamic for some, this would not excuse the underlying ideologies represented. The text does not offer alternative dynamics, but rather remains within the existing restrictive heteronormative narrative that reproduces the existing power structures within which gender inequality operates. Furthermore, the man is encouraged to participate in housework during this time not because he should in order to create an egalitarian relationship, but as a way to cope with her "wacky" mood swings so that he can "appreciate her happier mood" (172). The suggestion of his participation is not done with the woman in mind, but rather to do these things in service of himself so he does not have to deal with the pregnant woman's 
crazy mood swings. That the authors feel they must appeal to a narcissistic male ego in order to enlist his help rather than his simple human decency or compassion is telling of the stereotypically masculine construction to which the authors are appealing. The essentialist position of women and consequent dismissal of her emotions is just as troubling as the rigid gender role ideals the text seems to uphold. These underlying messages reinforce problematic stereotypes of gender dynamics ingrained in our culture.

Similarly, in another box to fathers, the authors continue to push an essentialist understanding of gender. The text states that when his partner is pregnant, the man also gets fluctuations in hormones, specifically "the female sex hormone" which is explained to "turn up the tenderness in males [and]...to bring out...[his] nurturing side" (222). The idea that the man will suddenly become more nurturing if his testosterone decreases and he gets a surge of "female" hormones operates on the assumption that women are naturally nurturing based on some uniquely biologically female component. The claim also rests on the assumption of a gender binary rather than addressing the fact that men and women alike produce both estrogen and testosterone, and that these hormone levels can vary over a wide range in each person's individual body. Instead, this intricate biological system, which exists on a scale, is introduced as a strict binary in the existence of a male and female hormone, implying that only when his partner is pregnant, does he also get a dose of the female hormone which makes him behave in more stereotypically feminine ways, namely more nurturing and tender. The belief in a gender binary is a necessary condition for the belief in strict and dangerous gender roles since the current patriarchal system of gender roles and power dynamics cannot operate without the existence of two distinct and separate genders that can perform and fulfill these polarized roles. 
The father is also reassured in one of his boxes that the woman's mood swings are something that she is "powerless to control" and are just a result of hormones, therefore occurring "for no apparent reason" (172). This description is uncomfortably similar to the condition of hysteria with which women have been historically and oppressively diagnosed (Showalter). The idea that the woman is a prisoner to wild and unreasonable moods based on no real feelings encourages the men reading these statements to feel comfortable and justified in dismissing the woman's experiences and ignoring the things that affect her, instead chalking it up to "those crazy female hormones." The idea that women are subject to unrelenting and unreasonable emotions because of their biological (hormonal) status as women has often been used to dismiss women, whether it was called "hysteria" or the more contemporary PMS. This cultural narrative has been used to oppress and dismiss women on the basis that female hormones made them too unpredictable and volatile, for example, attributing any complaint, critique, or otherwise inconvenient behavior to "that time of month" rather than considering emotions or critiques from the woman as a genuine concern.

\section{Gender Binary and Gender Essentialism}

Understanding gender as a natural binary, and the norms that flow from such understanding of gender as discussed above can be dangerous to women in our culture. When women and men are understood as wholly and intrinsically different and dichotomous categories, not only is the justification for equal treatment more difficult to make, but the polarization of these two genders is increased, further creating a distinct line between these two groups of people. Those who do not fit neatly into either of these oppositional categories are often met with negative social sanctions, stigmatization, or punishment. The system of rigid gender binaries 
creates a culture in which one gender (women) must then be submissive to and exist on a hierarchy below the other (men), if they are to count as "real" women. Therefore, reinforcing gender as a binary system only feeds a system that works to oppress women and punish anyone who do not conform neatly (and "naturally" - note social objections to transgender or gender nonconforming persons) into one or the other.

Not only is the way WTEWYE talks about hormones reinforcing an essentialist, binary understanding of gender, but the way it differently addresses men and women about hormones with respect to mood swings is concerning as well. When talking to the father about mood swings he may experience during his partner's pregnancy, which are "surprisingly common in expectant dads," he is reassured that while his hormones "can play a role...feelings factor in as well," reassuring him that the things he feels are valid and acceptable to be feeling (177). Alternatively, when talking to him about the woman's mood swings, she is described, as discussed above, as behaving erratically "for no apparent reason" (172). Similarly, when talking to the woman about her own mood swings, she is told, "blame it on your hormones" (172). Although there is a brief mention that the many changes she is experiencing could "exaggerate the swings," and "overwhelm [her] mood" (173) the text relies heavily on the assumption that what she feels is due to hormones and thus functions to invalidate her experiences and emotions.

Unlike the way the text attempts to explain male mood swings by introducing his validated emotions into the mix, the woman is painted as biologically unstable rather than acknowledging that she may have genuine human emotions. Thus the patriarchal ideology dominating the cultural thought is played out yet again in the text as the pregnant woman is not given the same consideration as her male partner and she is quickly dismissed. Assuming that a woman acts the way she does based on female hormone fluctuations rather than, perhaps, the 
stress of working the Second Shift, the stress of trying to conform to unachievable beauty standards, experiences of gender inequality, or any number of things allows women's valid concerns to go unaddressed and places women within a narrowly defined, "biologically" constructed box of gender from which she is unable to escape.

Participating in the essentialist narrative of men's naturally higher sex drives, WTEWYE mentions, as I cited earlier, the "raging sex drive" of the father in a box written to fathers (222). The belief that the man has a "raging sex drive" simply because he is a man feeds into the narrative that sex drives, like genders, exist on a natural binary. Quoting Emily Kane and Mimi Schippers, bioethicists Lisa Campo-Engelstein and Nadia Johnson note that Americans appear to believe that men's sexual drives are stronger than women's and at least half perceive those differences as natural, which is potentially important given the role that beliefs about sexual drives have played in justifying men's sexual aggression and in depicting women as generally passive (209).

Campo-Engelstein and Johnson go on to say that "suggesting that these differences in libido are biological and hence unchangeable is problematic because it tends to absolve men of responsibility for their sexual actions" (209). If we build ideas of unequal sexual responsibility and biologically gendered sex drives into our language and into our scientific and cultural understanding, we normalize, legitimize, and further disseminate problematic ideas that are clearly harmful to women.

Contributing to a system of thinking that reduces and sexualizes women can dangerously promote a culture of sexual violence, which could potentially lead to actual sexual violence. Communications and psychology professors Paul Wright and Robert Tokunaga found that exposure to objectifying portrayals of women predict "stronger attitudes supportive of violence 
against women" (955). Considering that WTEWYE heavily sexualizes women's bodies, it is possible that these ideas could be contributing to objectification and thus, potentially, "rapesupportive" attitudes. Even if "rape-supportive" attitudes do not manifest themselves as real perpetrated violence, they create a toxic culture that tends to silence women who are subjected to sexual violence, and even attempts to blame women for their own victimization. This is especially true under the prevailing narrative that "boys will be boys," which contributes to a misguided cultural understanding of gender and an assumption that men have naturally higher sex drives that they simply cannot control, an idea which appears to be gestured at in WTEWYE via comments on male sexuality such as the "raging sex drive." Through this lens, women come to be seen as the "gatekeepers of male sexual impulse" (Anderson and Doherty 8). If men are considered to have a naturally higher sex drive and are unable to control it, it is then up to women to control and manage it for them, and thus if a woman it raped, it comes to be seen as her fault for not properly controlling the perpetrator's behavior (Anderson and Doherty 8 ). The potential of the embedded ideas of sexualizing women's bodies and a biological essentialist understanding of sex to contribute to a harmful rape culture will be explored further in the concluding remarks. Once again, the importance of critically evaluating cultural language is clear, particularly when dealing with such a widely read text like WTEWYE.

\section{Body Image and Sexualization}

Several sections in WTEYE place importance on the woman's breasts as sexual objects. Most noticeably, women are told to wear a bra "even at night" if they have a "tendency to sag" in order to "protect them [her breasts] from a floppy future" (140-141). As many women would agree, bras are not the most comfortable clothing item to wear, so asking women to sacrifice 
comfort and wear a bra all day (and all night) for the sole purpose of maintaining a level of conventional attractiveness is problematic. Perhaps most strange is the absence of any mention that a woman may elect to wear a bra or not based on what is most comfortable for what are notoriously painful and tender breasts during pregnancy. Not only are women encouraged to wear a bra to keep breasts as "perky" as possible (140), there is not even an effort to blend this discussion in with a reason women may personally want to wear a bra, such as potentially providing support or relief to breasts which may be tender.

The assumption that the woman should forgo whatever is comfortable for the sake of staying attractive (as defined by culturally created idealizations of the female body) is degrading to women. This claim hinges on the idea that a woman's value is in her attractiveness, and here, more specifically, her breasts. The woman is asked to see her self-worth in the perkiness of her breasts which she must protect at all costs, even at the cost her personal comfort. While this is harmful to the pregnant woman in the immediate sense of any discomfort accrued by sleeping in a bra, the further implication that women's worth lies in her sexual desirability is a damaging concept that contributes to an already prevalent rape culture (Breger; Anderson and Doherty 10; Nichols, 1). The sexual objectification of women has been repeatedly demonstrated to contribute to rape culture - a culture in which rape is conceived of as an inevitable fact of life (Breger 3). For example, Wright and Tokunaga found that "attitudes predictive of violence against women vary as a function of men's exposure to objectifying media" (955). Normalizing messages of female sexual objectification to both female and male readers of WTEWYE therefore has the potential to unwittingly contribute to a rampant and toxic culture for women, again, discussed in greater length in the conclusion. 
The text also places importance on the growth of the breasts as a positive event for both the woman and her male partner, relying on the idealized woman as one with large breasts and a thin waist (outside of pregnancy, that is). In a section to the father, the text states that his pregnant partner's swollen breasts and hips make her feel "more womanly than ever" (196) and in another section explains that her breasts may have "swelled to thrilling proportions" (277) even if it is incredibly painful or uncomfortable for her body to be changing so rapidly. By drawing attention to the woman's breasts multiple times and using positive language cues (such as "thrilling"), the man is given signals for how he should be thinking about and experiencing the woman's pregnant body. This language also places undue emphasis on the woman's breasts as instrumental to male pleasure.

Thinking about women in this way is harmful since the man is asked to think of the woman's body as sexual and desirable despite how she may feel or experience it, and despite any pain she might be in, and further assumes that the woman herself likes large breasts as well. Moreover, the idea that the pregnant woman can be reduced to just two body parts that happen to be growing because of a biological process occurring within her is degrading and dehumanizing. She is not being viewed as an individual person, but as a mere body, and not even a complete body, at that. Additionally, assuming that breasts and hips are what make women feel "womanly" is reducing womanhood to narrow definitions of conventional female attractiveness defined by the male gaze. The ideology of patriarchy is evident in this claim, asking that we measure womanhood not by what women themselves individually define it as, but how attractive the culturally "normal" heterosexual male finds certain aspects of the woman's body.

Focusing positive attention on the growth of her breasts assumes that they are an important component of how he values the woman. Wright and Tokunaga note that "women are 
depicted as sexual objects when they are assigned the role of providing men sexual pleasure via their physical attractiveness and sexual accessibility" (956). When the male gaze is directed toward the woman's sexualized body as an appetizing object for the father, the text of WTEWYE promotes the degrading objectification that is already a prominent issue in the cultural understanding of women. As psychologists Irina Anderson and Kathy Doherty state, "rape is fuelled and legitimated by cultural constructions of hegemonic gender and heterosexuality and by 'rape-supportive' practices in institutional and mundane settings" (25). Therefore, the focus in WTEWYE on the woman's body reinforces harmful and problematic constructions of women as sexual objects already rampant in our culture. The intense sexualization of women both in WTEWYE and in culture more broadly contributes to the idea that women's true value is in their attractiveness, and can potentially become a component in structuring or promoting thinking which is prevalent in rape culture.

The woman's breasts are not the only aspect of body image that is discussed in WTEWYE. The authors assume that women consider a "speedy metabolism" a blessing (39), reinforcing gendered beauty standards that women should want to be thin. Several other comments throughout the text suggest this as well. For example, the text states that weight gain outside of the socially acceptable context of pregnancy is "depressing," signaling to women how they should feel about gaining weight outside of pregnancy (223). Again these themes are repeated with the suggestion that watching yourself gain weight during pregnancy is something you are "dreading" after "years of dieting" to stay thin (177). These assumptions and discrete key phrases signal to the woman reading WTEWYE that a woman ought to be constantly worrying about weight and appearance. The text revisits the concept of moralizing weight gain and framing weight gain outside of pregnancy as negative when, after attempting to assure women 
that pregnancy is one time that weight gain is a positive event, the text adds, "if there were ever a legitimate reason to pile on the pounds" (178). This language, rather than promoting overall healthy lifestyles and body images, makes pregnancy into a single exception for gaining weight which the woman is quickly expected to shed after childbirth (180).

Furthermore, in a section on body image, the woman's weight is coded as either good or bad depending on context. The text reminds women that there is "a very important difference between pounds gained from...too many midnight dates with Ben and Jerry" and the weight "gained from making a baby" (223). The text adds that the woman should enjoy her pregnant body not because her body is doing miraculous things, or because her body is a wonderful part of her complete being, but because in the minds of many people, the "rounded silhouette" of a pregnant body is "among the most sensuous of female shapes" (223). Suggesting that women should enjoy their bodies based on the assertion that other people find it sexually attractive asks that women minimize their self-worth to the pleasing qualities of their bodies in an already toxic culture in which women are constantly equated with the attractiveness of their bodies. Rather than using a section titled "Body Image" as an opportunity to promote a healthy body image in women in an effort to combat some of the invasive cultural pressures, the woman's weight is viewed only instrumentally, as long as it is in the service of a valued fetus.

What is even more problematic is the statement that her silhouette is what is attractive. Considering that a silhouette is simply an outline of a shape, the woman is asked to value herself not only based on her body's attractiveness, but to further reduce her sense of value to the mere outline of her body so that she now becomes a faceless, depersonalized shadow whose outlines are aesthetically appealing to the general public. In other words, the woman is instructed to value herself only after she has been effectively erased from sight until all but the "sensual" outline of 
her body remains. Promoting ideas of thin, beautiful, big-breasted women only reinforces harmful beauty standards which create a constant state of pursuing an essentially unattainable goal and therefore low self-esteem, self-worth, and unhealthy body images, potentially leading to depression or even eating disorders. All of these comments function in different ways to maintain women's place within the oppressive patriarchal system of gender norms that limits and devalues women as human beings.

\section{Class and Motherhood}

In a section addressing military families, the text suggests that, unlike their deployed military husbands who just do not "have the time to scroll through pages of cribs, strollers, and monitors" (37), pregnant women have ample time and money to shop for baby accessories, promoting the sexist narrative of frivolous women and hard working men. In making the assumption that the woman is naturally in charge of home care and child-related activities (such as getting kids to school) the text implies that the woman's career, if she has one, is secondary to the father's career. Placing the woman's career as secondary to the man's speaks to structures that maintain patriarchal hegemony in our culture. Suggestions such as those to buy groceries online further assume a middle-class standing, reinforcing the idea that, as Dobris and WhiteMills put it, the proper place for a woman is "one of middle class privilege" (27). This construction sets up the expectation of middle-class women as the ideal, proper image of motherhood, to the exclusion of women who exist outside of this narrow definition.

Moreover, strict understanding of family roles and structures reinforces the image of a heteronormative middle-class family as the "proper" family dynamic in which to have children. This reinforcement of "proper" structures is done by assuming that the woman has the support of 
a husband who in turn makes enough money that the wife need not work or may work minimally as to have time to shop, take care of the home, the children, and still get plenty of rest. The assumption that this family can afford new baby furniture, which is often expensive, and for which they are presumably shopping from the comfort of a home computer, further assumes middle-class status. This is especially troubling in light of "enduring eugenic attitudes about women deemed unfit to bear children," as the women often targeted as those unfit to have children are working-class women of color (Solinger 245). When motherhood is constructed as belonging to a middle- or upper-class domain, women who do not fit into that narrative are depicted as unfit mothers and are negatively socially sanctioned and excluded from the discourse (Dobris and White-Mills 27; Flavin 141-2; Woliver 145, 152; Ayala and Freeman).

That motherhood is culturally constructed as the apex of a woman's life further complicates motherhood for women who exist outside of the middle-class, since they simultaneously receive the message that they should want to be mothers and yet they are unfit and not socially acceptable mothers (Flavin 142). The text further suggests that the working woman may want to be moved to a different, less noisy, strenuous, or toxic position or even take an early maternity leave (206-207, 209). While encouraging women to stand up for themselves in the work environment could be a positive message, these suggestions seem to imply that the working mother has the power and freedom within her job role to accomplish these changes, even though she may not actually be within a power dynamic from which she could control these situations. In such cases, warning women about negligible risks over which they have no control could be unnecessarily anxiety producing.

Urging women to change things in her job to avoid occupational hazards is not only anxiety producing, but also takes a social risk, which is out of the woman's control, and places 
the responsibility squarely at her feet. Additionally, working-class women are more likely to face the most occupational hazards, have the least amount of power in their position to do anything about it, and likely rely more heavily on the income they produce from the hours spent on their job, especially if the woman is a single working mother (Woliver 144-154; Wolf 622). The individualization of this risk, as women's and gender studies professor Joan B. Wolf states, asks us to see "good health [as] an indicator of discipline, self-control, and wise choices," despite the often social and political causes of poor health (613). Thus, any complications or deviations in her fetus or her pregnancy will be seen as a moral or character flaw in the woman. An “imperfect" fetus is the woman's fault — the result of her not changing her workload or failing to obtain a different position in the company, move to a safer neighborhood, or purchase food unavailable to her.

\section{Fetal Environments and Fetal Personhood}

In her book, Recreating Motherhood, sociologist Barbara Katz Rothman famously argues that within the cultural ideology of technology women are depicted as "depersonalized mothermachine[s] being manipulated to efficiently produce babies out of valued sperm" (34). This ideological construction of women's bodies is perpetuated in WTEWYE with phrases like "your body starts cranking up that baby-making machine" (3), and "your body is gearing up for the months of baby making to come" (122). If women are viewed simply as fetal environments by both themselves and others, their bodies constructed as baby-making machines, our culture has effectively dehumanized women into objects to be used and monitored for reproduction.

The ability to visualize the fetus through ultrasound has lead to a dangerous cultural shift for women. Susan Sherwin, a well-known feminist philosopher and bioethicist, remarks in 
"Normalizing Reproductive Technologies and the Implications for Autonomy," that "when fetuses can be viewed as separate beings, they can be treated as such and pregnant women are reduced to 'uterine containers' or 'fetal environments"' (102; see also Rothman; Wetterberg; Petchesky; Duden). The language in WTEWYE reinforces a passive role for the woman in her pregnancy, framing it as if she is a spectator to something belonging to the fetus when she is "welcome[d] to [her] pregnancy" and told to "sit back, relax, and enjoy" while her body is "gearing up" to make a baby (122). The idea that the woman somehow exists outside her own embodied experience of pregnancy as a passive spectator maintains the notion that she is present only insofar as she provides an environment for the fetus. Further, the development and use of technology that allows physicians to treat the fetus as a patient separate from the woman reinforces the "construction of the fetus as a social entity, with characteristics and needs that are independent of the pregnant woman" (Wetterberg 32). Enforcing the idea that fetuses are completely separate and autonomous beings from the woman's body is troubling since, as philosopher and bioethicist Laura Purdy points out, "[s]ome writers conflate fetuses and children, unable to see any morally relevant differences between them: they seem oblivious to the fact that fetuses live in women's bodies" (Purdy 66). When such high value is placed on fetuses as individuals, the woman in whom it resides is gradually erased from her own experience of pregnancy.

The ability to visualize the fetus has challenged the boundary of what is considered inside and outside of the woman's body (Petchesky 272) and allowed the fetus to be culturally constructed as an autonomous individual with rights and interests of its own. Not only has the widespread use of fetal ultrasounds contributed to the troubling cultural climate at hand, but this occurred in spite of FDA recommendations against the routine use of fetal ultrasounds 
(Petchesky 273; Sherwin Reproducing 103). As an effect of being able to visualize the fetus through ultrasound and imaging technology, images of fetuses began being widely used. As political scientist Rosalind Petchesky notes, however, "from their beginning, such photographs have represented the fetus as primary and autonomous and the woman as absent or peripheral" (Petchesky 268). These images have contributed to the dangerous cultural idea of the fetus as separate and autonomous from the woman's body, since the fetus is consistently rendered alone and, as Petchesky quotes Rothman, the mother has therefore become "empty space" (270). Often in fetal representations, the woman is literally erased from the pregnancy, which affects how people come to understand a woman's role in the experience of pregnancy.

Images of these free-floating fetuses are present throughout WTEWYE (see fig. $2 \& 3$ ). There is a chapter for each month of the pregnancy, and the first image in each chapter is an image of an enlarged, free-floating fetus, characteristically surrounded by empty space. The title of each of these images is "Your Baby, Month [x]." Not only is the image of the autonomous fetus sending important messages about the value of the woman in the pregnancy, but the linguistic construction of the fetus as an already born child by calling it a baby heightens the importance and the emotional and cultural value of the fetal "person." The word "baby" implies that the image being viewed is one of an individual child existing outside of the mother's body and therefore has conferred a different, higher moral and social status. Associating these meanings with an illustration of how a fetus develops into a baby once again sends clear messages about how readers should view and think about the image before them, even if it hardly resembles a human at all.

Not only are these free-floating fetal images included at the beginning of each chapter, but there is another box on the following page of each month's chapter labeled "Your Body This 
Month" (see fig. $1 \& 4$ ). These images, like the "baby" pictures before them are not value-neutral and send distinct messages to the woman reading WTEWYE that her fetus is really the only thing of value in this experience, and that she is only important insofar as she is an environment for her fetus. The most striking thing about these images is that it is of a headless woman's torso. Although the title of the box indicates that this image is about the woman's body "This Month," only her breasts and stomach are included, and the only internal anatomical structures featured are her bladder, her vaginal canal, and her uterus, once again with an illustrated fetus residing within. The focus of this box, then, is clearly the uterus and more specifically the fetus within. The woman is again devalued here as the image signals that what is of importance or value here is actually the fetus and anything relevant to it, specifically the uterus and, later on, the breasts. The woman herself is not depicted as a complete human being. She is depicted as a torso in which the fetus resides, reducing her to a fetal environment. Her body is only of importance insofar as it supports the highly valued potential life inside of her. This message is all the more troubling considering the label on the illustration indicates to the woman that this image is the one about herself, and yet proceeds to marginalize her and elevate the fetus

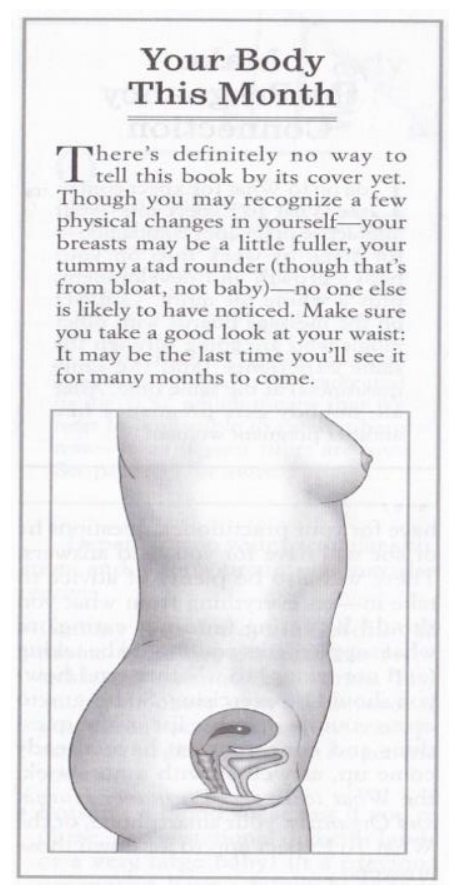

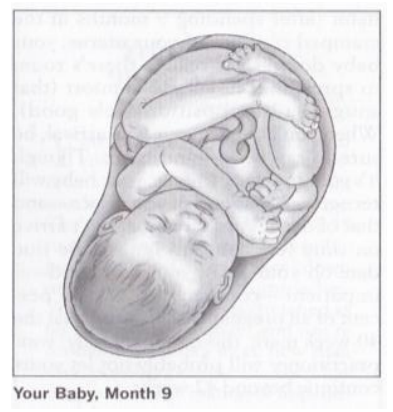

Fig 2. "YourBaby, Month 1" Murkoff and Mazel, p. 123

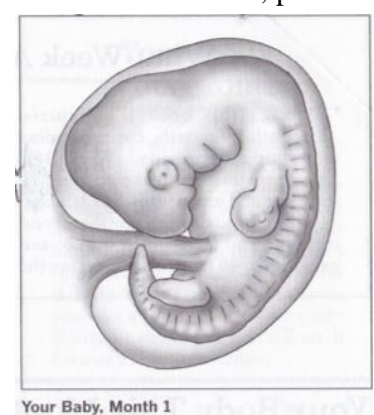

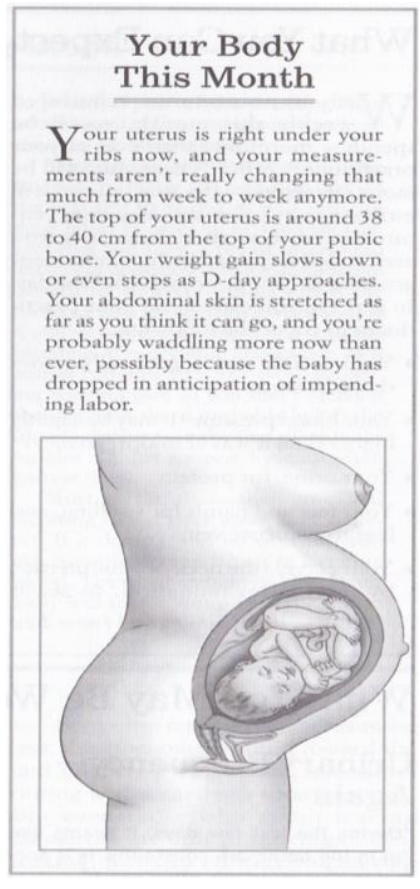


Fig. 1, "Your Body This Month Murkoff and Mazel, p. 125
Fig. 3, "Your Baby, Month 9"

Murkoff and Mazel, p. 373.
Fig. 4, "Your Body This Month"

Murkoff and Mazel p. 375.

Bioethicist Susanne Brauer notes the consequences of fetal images and reproductive technology, stating that pregnancy has become an experience commandeered by technology and "technological observations, which make it possible to omit the subjective experience of the woman from medical discourse, devaluing her specific experiences and relationship to her fetus and body" (Brauer 48). With the focus and importance placed on the fetus rather than the woman, she is framed as a potential risk to her fetus. It then follows that she must be monitored and made into a more safe and efficient environment for the fetus, increasing surveillance of the woman and at times, resorting to risky and unnecessary medical procedures for the sake of the fetus, such as forced unnecessary emergency $\mathrm{C}$-sections. Being able to visualize the fetus long before it is born as a baby also "disrupt[s] the very definition as traditionally understood, of 'inside' and 'outside' a woman's body” (Petchesky 272). The fetus then becomes more real while the woman's body becomes more invisible.

Throughout WTEWYE, women's actions and decisions are depicted as creating a risky environment for the health of their highly valued fetuses. Perhaps the most explicit example of this is telling women "early labor may be the body's way of attempting to rescue the baby from an unhealthy environment" (33). This statement was made in reference to women with STI's, suggesting that a woman's perceived sexual deviance can turn her body into an uninhabitable place for her fetus. By not referring to women as people but rather "unhealthy environments," women are dehumanized and depicted as potentially risky to their pregnancies by perpetuating the idea that they are merely places for fetuses to live (Brauer 48), and dangerous ones at that. 
With respect to the highly valued fetus, the devaluation of the woman in her own pregnancy is a dangerously easy conclusion to make and justify once women are reduced to mere machines. Dehumanization of women can also contribute to the devaluation of women in clinical settings - a place already ambivalent to women's unique medical concerns (Morgan; see also Haslam on Dehumanization). The dehumanizing metaphors of the woman's body as a reproductive machine and the dehumanization that occurs when reducing women's presence in their pregnancies, as well as objectifying their bodies, all of which are themes manifest in WTEWYE, come together to create an increasingly troubling picture of how WTEWYE contributes to and reinforces a problematic and dangerous ideological construction of women.

\section{Risk and Surveillance}

As discussed at length above, visualizing the fetus through ultrasounds has contributed to the construction of the fetus as an individual with needs that are at times different from the mother's. Mother and fetus are therefore placed in opposition to each other and the needs of the mother are depicted as less important. The mother is no longer trusted to act in the best interest of her fetus and "her behavior must therefore be monitored" (Wetterberg 36). The idea that women can't be trusted with their own bodies is a long-standing assumption in the medical establishment, and is much worse for women of color (Morgan). The use of "high-handed treatment" to women in clinical settings due to this general lack of "fair consideration of women's interests in much of medicine" is likely to continue if the social issues at the root of these assumptions are not changed (Purdy 72). That mothers provide a source of potential risk to their fetuses also provides justification for the policing of women's bodies during pregnancy out of concern for the valued fetus. Women are so devalued in their own pregnancies that WTEWYE 
even asks women struggling with depression "could there ever be a good reason to put your emotional wellbeing over your baby's physical well being?" (44). The text goes on to explain that if their depression "can't be treated effectively in other ways" (45) and poses a risk to the fetus, low doses of antidepressants may be used under strict physician surveillance. However, this still invalidates the woman and her health, as her "health is only instrumentally valued" (Ayala and Freeman 131).

Even more harmful is the promotion of instrumental weight gain in a section on eating disorders where women are encouraged to overcome eating disorders for the health of their fetus (40-44). Although the authors do include reminders that overcoming an eating disorder is good not only for the health of the fetus but also for the woman herself, the overall message is that the motivation here is the health of the fetus, which just so happens to also be healthy for the pregnant woman, rather than encouraging her to overcome an eating disorder for her own health and value. The idea that the "baby's wellbeing depends on your wellbeing" (44) on the surface seems to be valuing the woman's health, however, the apparent motivation is to be healthy because the fetus needs it, not because the woman's personal health is important.

Even after childbirth, the woman is encouraged not to slip back into disordered eating habits because it can "interfere with your ability...to parent effectively and to produce enough milk" (44) which again is an instrumental valuation of the woman's health. These messages suggest that women ought to view themselves not as inherently valuable individuals but only insofar as they are useful to the fetus inside of them. The danger here exists in the valuing of women based on their reproductive capabilities rather than their innate value as humans since this method of valuation raises the status and importance of the fetus while reducing the importance of the woman to a fetal environment. Placing the mother as less important than and 
in opposition to the fetus's unique needs in this way once again constructs women as a potential risk or threat to their own fetuses (Wetterberg, Purdy).

WTEWYE paints the world as a minefield of risk for women to avoid. Women are warned of BPA in cans (76), caffeine intake (63), herbal tea (113), forbidden to drink alcohol (65) or eat sushi (109), and are directed to avoid almost every food from processed meat to unwashed raw produce (118), leaving you wondering what women are actually supposed to eat while pregnant. Women are encouraged to "have [their tap lines] tested" (75), advised against electric blankets, hot tubs, or "extremely hot baths" (72), warned of air pollution (77), told that smoking essentially traps the fetus "in a smoke-filled womb" (66), and are even told not to walk and use phones at the same time in case they might lose their balance and fall over (71). Furthermore, many of the warnings given throughout the book, such as those against herbal tea, alcohol, or sushi are based on wildly misrepresented studies, flimsy evidence, or no evidence at all. For example it is a common belief that pregnant woman should not consume any alcohol, however, the study from which the belief originates was done on heavily alcoholic women. In fact, no study has yet proven that moderate amounts of alcohol raise the risk of birth defects (Richardson et al 131), and some people point out that de-stressing with a glass of wine is more beneficial than abstaining from alcohol during pregnancy since stress can have demonstrably negative effects on pregnancies.

Women who do not successfully navigate this minefield of risk are construed as bad mothers who are setting their children up for a lifetime of difficulty (Kukla). Nowhere is this trend more clearly stated than when WTEWYE claims that a pregnant woman's smoking, or even inhalation of second-hand smoke, can affect her future child "into adulthood" and can even affect her daughter's pregnancies "later in life" (67). Throughout all of this, the burden is 
completely placed on women to avoid or fix these risks to protect their fetuses, something that is “every expectant mother's most basic instinct" (70). This statement on instinct implies that women are innately mothering and again appeals to an essentialist construction of women as mothers, reinforcing gender roles as previously discussed. This thinking can also restrict women from pursuing fulfilling careers or devalue women who have made a choice to pursue her career. The concept that women are innately mothering is dangerous for women because it perpetuates norms that condemn women who may not want to be mothers or who are alternatively not able to become biological mothers. When strict, essentialist ideology is reinforced in the culture, women who fall outside of the given norms come to be seen as "bad" women and face harmful stereotypes or negative social sanctions.

Not only does this claim encourage people to think about women in an idealized patriarchal framework of women as instinctually, naturally mothering, but it also shifts most, if not all, the burden of responsibility for risk management onto the individual mother by intimating that good mothers protect their fetuses at all cost. Rather than pointing to BPA or air pollution as social issues, it is framed as women's responsibility to buy foods that are "packaged in glass jars" (77), "limit time spent outdoors" during poor air quality, "keep indoor air clean," and to "choose a [new] route" on which to exercise that avoids "congested roads" (77). This conception of risk places the burden on individual mothers to avoid risks that are created by social issues or large companies. This is what rhetorician Marika Seigel would refer to as the “individualization of social risks" (101). Prevailing narratives of medicalization in an individualistic culture encourage people to take full responsibility for their health and wellbeing even when many of the causes are beyond their personal control (Ayala and Freeman; Conrad; Wolf; Lock). When WTEWYE uses language that places pregnant women under full 
responsibility (and thus constant anxiety and self-monitoring) for reducing socially created risks, such as BPA, tap water lines and air pollution, in a "pursuit of zero risk to the fetus" (Lyerly et al 40), the text reinforces the dynamic of oppression that Frye described as the "fatal combination of responsibility and powerlessness" (9). Although women bear the responsibility for fetal outcomes, they are in a position from which they are unable to control much of what happens to them or their fetuses.

By safely locating risk within individual bodies, blame and risk management are effectively removed from the structures that produce risk in the first place (Seigel 101; Richardson et al). Purdy notes this cultural trend, declaring that "the moral basis for such responsibility is shaky while corporations spew dangerous pollutants into the air" (Purdy 71). If we see health as located within and as faults of individuals, we overlook many factors that create health problems, as well as protect the institutions that continue to oppress and negatively affect populations (Lock). Instead of addressing the structural issues at play, women are constructed as the main risk factor in their own pregnancies, and are further asked to avoid and minimize every possible risk for the sake of their fetuses. Medical anthropologist Margaret Lock contends that instead of this individualistic model, we ought to understand health_particularly women's health — as the politically situated thing it is, properly move responsibility to institutions, and begin addressing the structural issues affecting health.

\section{Reproductive Technology}

Rhetorician Mary M. Lay and co-authors make note of how "[s]ociety has used technology to confirm and support women's subordinate position, illustrating the ideological link between technology and masculinity" (Lay et al. 11). WTEWYE attempts to normalize 
technological interventions in pregnancy with signal phrases such as "most expectant moms (even those considered at low risk of having a baby with a defect) undergo several screening tests during their 40 weeks" (53). This normalization of medical technology also encourages pregnant women reading the text to submit willfully and obediently to the technological methods of maternal surveillance, which are complicit in maintaining patriarchal control over women's bodies and reproduction. In discussing genetic screening, the authors of WTEWYE explain that for most disorders only one parent needs to be tested, and that "testing the second parent becomes necessary only if the first tests positive" (48). Later on, however, the authors say "again, no need to test dad if mom is negative" (49), clearly signaling that it is the expectation that the woman's body ("mom") will be subjected to the tests, screening, and surveillance, and only then will "dad" be expected to submit to the medical establishment. This language further normalizes the concept that women's pregnant bodies are risky and ought to be monitored closely.

The marginalization of women in their own pregnancies and the invalidation of women's concerns and knowledge of their own bodies can effect how women experience clinical interactions. As Rothman points out, reducing women to fetal containers and baby-machines creates a need for "managing bodily functions" and physicians, through "controlling her body with drugs and even surgery" are able to make labor "more efficient, predictable, [and] rational" (31). This increased surveillance and medicalization of pregnancy, combined with the normalization of such practices has lead to the widespread acceptance of: ultrasounds, which work to reinforce the mother/fetus separation; the unnecessary use of fetal heart monitors which require laboring women to be strapped down in an uncomfortable position and has caused an increase in unnecessary C-sections (Sherwin, Reproducing); and even the use of Pitocin to speed 
up delivery by causing harsh, artificial, and painful contractions, which then often cascade into needing a c-section.

Treating women's bodies as machines to be managed and fetal environments to be monitored devalues and dehumanizes the woman. The technology is not used so much with the woman or her health in mind, but only with regards to what is best for the fetus or more convenient for clinical practice. For example, fetal heart monitors, originally only used in highrisk cases, have become normalized and widely used despite the fact that they do not improve the health outcome of the baby (Sherwin 104; Purdy 70; Petchesky 271; Lyerly et al 37). They do, however, cause an increase in unnecessary $\mathrm{C}$-sections because of the ease with which the readout can be misinterpreted. Clearly, it would typically be in the laboring woman's best interest to be able to labor in whatever position is most comfortable for her, and to not put women through unnecessary surgeries. Since the technology is not used for the safety or comfort of the laboring woman, then, the woman's body is being treated with no consideration as to what would be best for her. She is treated as an object - a machine - that can be hooked up to other machines to make the process cheaper and more efficient (Rothman). For example, using fetal heart monitors instead of data gathered by practitioners makes monitoring labor cheaper and more efficient since one person can watch screens of several women at a time. This only perpetuates the idea that women are not complete persons deserving of respect. As Purdy aptly notes, this system is "another proof that women are still second-class citizens" when Americans have more control over their corpses than women do over their pregnant bodies. Purdy cites Rhoden's example that "an organ taken from a cadaver can save a life just as any emergency cesarean can" (73), however women can be made to have a cesarean against their will while a person's wish not to donate their organs is respected even after death. Additionally, Purdy calls attention to the 
unsound reasoning that has lead to judges ordering medical interventions in women's pregnancies on behalf of the fetus, while on the other hand, judges refuse to order similar medical interventions of parents for the benefit of their already-born children (68).

Although there are many issues with the ways in which medical technology functions within the prevailing patriarchal culture, it is worth noting that women themselves have often welcomed the technology and are often more than willing to do almost anything for their fetuses. This, however, does not derail the argument laid out here. In his well-known essay, "Ideology and the State" Althusser discusses how ideology functions in such a way as to reproduce itself in culture by making us believe we are choosing when in reality we are simply following along, perpetuating the ideology without even realizing it. Put another way, Frye points to the fact that oppression functions by restrictions that are often "internalized and self-monitored" so that those who operate under the harmful ideology are the ones perpetuating it. Since humans are influenced by the cultures and structures around them, pregnant women's “choices generally reflect and often support the existing power structures" (Sherwin, Reproducing 111). Since decisions are not made in a vacuum, we must remain cognizant of how popular language such as WTEWYE functions to perpetuate prevailing ideologies.

Further, the pregnant woman's willing participation in and perpetuation of these ideological structures reflects Michel Foucault's well-known idea of biopower — that the body is a site of social control and is both self-monitored and socially monitored (Lay et al 4; Wetterberg; Herrle-Fanning 32). Foucault argues that this internalization has a "'normalizing' and 'regulatory' function" within the prevailing culture (Herrle-Fanning 32). The internalization of these ideologies, then, is not surprising, but is in fact expected. Sociologist Anna Wetterburg even makes note of the "significant role" (44) pregnant women's "active participation" (29) 
plays in "perpetuating these standards" of strict surveillance and risk avoidance for their fetuses (44) and how the use of pregnancy guides reinforces to women cultural expectations for how "responsible pregnant women should behave" (45). The language in WTEWYE certainly falls into this category, as the theme of constant vigilance and surveillance is consistently played out within the text.

\section{Conclusion}

While I am confident that the authors of WTEWYE did not set out to write a book that participates in the many harmful structures outlined above, the language used in WTEWYE nonetheless reinforces many problematic ideologies and themes such as harmful gender norms and stereotypes, heteronormativity, and biological gender essentialism. Additionally, the text reinforces objectification of women's bodies, and assignment of personal responsibility for all [social] risks. The idea of women's bodies as an instrumental means to an end, the increased surveillance of women's bodies, normalization of technology and the erasure and marginalization of women from their own experiences of pregnancy are also all problematic ideas which are present in the text of WTEWYE. As discussed above, cultural ideologies work in insidious ways as to appear harmless and natural. With this in mind, it is therefore increasingly important that we are aware of how the language operates in such a text.

The use of gender norms subtly reinforces their cultural effectiveness. These norms can limit what roles women pursue in our culture, reinforce a gender hierarchy that is oppressive to women, dangerously equate womanhood to motherhood, define female value by sexual desirability, and promote rape culture. If these gender norm performances and hierarchies are continually reinforced through cultural language such as in WTEWYE, the systems that create 
oppression and influence gendered violence against women are effectively maintained.

Considering the above analysis of the text of WTEWYE, I will now take a moment to speculate on the further possible implications that the themes in the text could have in relation to a culture of violence, particularly sexual violence, against women.

As I have argued, WTEWYE maintains and reproduces many harmful gender norms and promotes a binary, essentialist understanding of gender. Law professor Melissa Breger argues that gender norms and implicit biases against women are rampant in our culture and are a critical component in creating a culture that "condone[s] violence against women" (3). After all, gendered violence "does not occur in a vacuum" (Parrot and Cummings 23). The World Health Organization cites the United Nations' definition of violence against women as:

Any act of gender-based violence that results in, or is likely to result in, physical, sexual or mental harm or suffering to women, including threats of such acts, coercion or arbitrary deprivation of liberty, whether occurring in public or in private life (WHO.int). This definition makes clear the enormous range that the phrase "violence against women" covers, and helps to shine light on how extensive the problem of gendered violence is. Although our culture may legalistically be opposed to violence against women, it nonetheless indicates that "such behavior is acceptable" through implicit messages that "normalize controlling or violent behavior against women" and through the perpetuation of gender norms (Breger 2-3).

In a meta-review of studies describing various factors that influence violence against women, sociologists Michael Flood and Bob Pease note the consistent, oft-cited connection between men who hold more rigidly to "misogynistic gender-role attitudes" and a greater probability that they will use domestic or sexual violence against women (126,128; Ward and Lundberg-Love 62). Women's beliefs in and adherence to traditional gender norms also make it 
less likely that women will report violence, and narrow stereotypes of gendered violence can even prevent women from recognizing their experiences of violence as such (Flood and Pease 127). Flood and Pease also describe how other cultural factors reinforce community tolerance for violence against women "includ[ing] advertising and language" (135). Since language is influential in both male and female treatment and experience of gender roles and, possibly, violence against women, it is important that we recognize and call attention to how the language around women's bodies present in WTEWYE could potentially lend itself to an existent, problematic way of speaking about women in our culture that tolerates, ignores, or promotes gendered violence.

While there are many forms of violence against women, of particular relevance to our culture is that of sexual assault. In fact, of the industrialized world, "the United States has the highest levels of reported rape," at a rate of "about 18 times higher than England and 9 times higher than that in Canada" (Grothues and Marmion), which is even more disturbing considering that most cases of rape go unreported. By conservative estimates, it is understood that 1 in 5 women will be sexually assaulted in her lifetime. The United States has a rampant "rape culture" which, as Breger defines it, "is one in which we presume that sexual violence against women is not only a fact of life but is...inevitable" (Breger 3). Rape culture is created through images (such as certain advertisements or pornography), the ways in which media reports rape cases (e.g., victim blaming), the language used in songs, movies, or more generally in conversations to talk about women, their bodies, and sexuality, and any other cultural factor that contributes to the pervasive idea that women are sex objects, commodities, and exist for male dominance and pleasure, making sexual assault seem natural and inevitable. The intense sexualization of women's bodies throughout WTEWYE could possibly have dangerous implications for women 
since men's “attitudes supportive of violence against women were mediated by their notions of women as sex objects" (Wright and Tokunaga 955). Advancing the idea that the male gaze defines a woman's sense of womanliness is sexually objectifying and could be playing into the cultural ideology that contributes to a prevalent rape culture in the United States.

Another avenue through which the language in WTEWYE could conceivably be taking part in a dialogue that promotes gendered violence is through essentialism and dehumanization. Psychologist Nick Haslam discusses in "Dehumanization: An Integrative Review” the phenomenon of infra-humanization, which occurs when people "actively avoid attributing" and recognizing secondary emotions in people who are not part of their ingroup (255). This is a unique type of dehumanization because it is "subtle" and can occur "in the absence of intergroup conflict" which extends "well beyond the context of cruelty and ethnic hatred" commonly associated with dehumanization (Haslam 255). Since people avoid attributing emotions to those considered to be in outgroups, it places people in the outgroup outside the "boundaries of moral consideration" in the minds of the ingroup, potentially leading to violence, dismissal, and oppression (Haslam 255). This way of thinking can stem from polarized group divisions such as the gender binary, which clearly creates two opposing and, by definition, exclusive, groups. Considering that "an essentialist understanding of social groups is a prerequisite for infrahumanization" (Haslam 259) and that dehumanization is "an important precondition or consequence of violence" (Haslam 255), it is alarming that WTEWYE pushes essentialist understandings of gender to both male and female audiences. Particularly troubling is the use of gender essentialism to address male readers, since it is a masculine patriarchal ideology that keeps patterns of gender inequality in place. 
In addition to violence against women as a general phenomenon, the pregnant woman's body is vulnerable to the unique clinical violence of unnecessary and painful medical interventions, and the indirect violence incurred when women's bodies are viewed as fetal environments and machines. The dehumanization of these processes can, as discussed above, also contribute to a culture of gendered violence. Further, these constructions of pregnant women can result in the marginalization of the pregnant woman within her own experience of pregnancy through the appeal to fetal personhood. The increased surveillance of her actions cause unnecessary anxiety, and relocates responsibility for social issues within the woman's body.

While the above connections between the language in WTEWYE and a culture of violence against women are purely speculative, the fact that these connections are at least conceivable provides a compelling area of future investigation. Although it is clearly beyond the scope of this study, and perhaps impossible in any context, to prove that the language of WTEWYE contributes directly to rape culture, the subtle (and not-so-subtle) promotion of things like strict gender roles, devaluation of women in their own pregnancies, sexualization, and dehumanization of women in the text seems to participate in a broader cultural dialogue around women that does contribute to rape culture and an unhealthy view of women in our culture. Even if the connection is not immediately compelling, the constructions of women in the text are problematic on their own, as demonstrated above, and further, it is best not to participate in or play with such a dangerous linguistic fire already engulfing our cultural understandings of women and gender. Instead, we ought to consciously strive to put out that fire-actively keep it from spreading, smoldering, and burning itself deeper into our cultural understanding of women.

That the text of WTEWYE continually encourages full bodily submission to the medical practitioner is problematic in light of the history of women's traditionally rocky relationship with 
clinical medicine, including increased medicalization of women's bodies (Conrad) and unnecessary medical interventions (Sherwin, Reproducing). Furthermore, the vulnerability of women in the clinical relationship presents another danger to pregnant women. Women can be prosecuted and jailed for "fetal harm" due to substance abuse, among other things, during the pregnancy (Woliver 136-154; Solinger 243; Haslanger). If arrested, a woman risks losing custody of her children, despite the fact that women's substance abuse is “often related to their poverty, their experiences of violence, their position in patriarchal and racist institutions, cultural and social norms, and their interpersonal relationships" (Woliver 150). Pregnant women are thus placed in a double bind - either protect herself at the expense of being labeled a bad mother for not getting the "best" prenatal care via honesty and vulnerability, or submit wholeheartedly, making herself more vulnerable to her practitioner at the expense of her personal loss of autonomy.

In a culture where pregnancy has been heavily medicalized and where women's pregnant bodies are already under constant surveillance by themselves, the medical establishment, and even strangers, the promotion of surveillance in WTEWYE is problematic. The surveillance of the pregnant body is promoted in WTEWYE with phrases like "if your practitioner supports you..." (30), "make sure you clear it first with your ob" (79), and "don't use [herbal supplements] unless they've been cleared by your practitioner" (83). They even suggest that women "check in" with their practitioners for a "coffee quota" (63). Throughout the text, women are relentlessly reminded to check with their physician before doing even simple things like coloring their hair (149). The constant reminder to take the physician's word as absolute on every aspect of the pregnant woman's life privileges the authority of medicine over the woman's own experiential 
knowledge. In fact, it teaches women to "rely on medical interpretations of their experiences" (Sherwin, Reproducing 100) rather than trust their own embodied experiences of pregnancy. Reinforcing the ideology of medical science as the highest authority not only reflects anxieties over lost power and an attempt to reinscribe that power as discussed earlier, but is additionally dangerous to women since the medical system is profoundly flawed in its approach to women's bodies, as a system that works to silence women's experiences and bodily knowledge (Morgan 84). These "knowledge systems of high-tech medicine often devalue women's experiential knowledge and embodied knowledge, that is, their unique experiences with birthing their children and their knowledge of their own bodies' signs and needs" (Lay et al 6). Therefore, using language that consistently focuses the woman's attention back to the absolute authority of their practitioner functions to perpetuate an uncritical submission to a highly politicized, hierarchical institution that devalues and suppresses women within an existing cultural climate of female oppression (Morgan 92). Women are already at a distinct disadvantage in clinical settings due to the ideologies of patriarchy (Corea, Reproductive; Sherwin, Gender 223). Women are more likely than men to be treated with dismissal and their medical concerns heard as "whining" which can have harmful consequences — not only does this damage the woman's trust in the medical relationship, but it can cause incorrect medical diagnosis, incorrect treatment, overtreatment, or no treatment at all (Sherwin, Gender 224).

Within a broader cultural context, ever increasing surveillance and policing of women's bodies can have further harmful consequences when, for instance, law enforcement officials take a fetus' health into their own hands and in doing so enact very real violence upon the pregnant woman through actions like court ordered C-sections, arrest (Woliver; Flavin; Rowland; Haslanger; Solinger 242-6), or even forced or coerced contraception or sterilization of women 
deemed "unfit" to be mothers (Woliver 147; Flavin; Gordon; Solinger 242-6). Rather than placing women in rehab programs for substance abuse, they are criminalized and arrested. Philosopher Sally Haslanger cites several disturbing stories, such as a woman in active labor having her legs strapped together by police, brought to the hospital, and forced to have a Csection because they claimed that her VBAC (Vaginal Birth After Cesarean) was too dangerous for the fetus (the woman later successfully delivered vaginally). She cites another story of a woman given 20 years in prison for feticide after having a miscarriage, and another woman who was charged with feticide after attempting suicide. Since women's bodies are particularly vulnerable to multiple forms of violence and oppression, especially in pregnancy, I reiterate that it is crucial that the language in texts like WTEWYE is evaluated critically and named for what it is in order to revoke some of the ideological power that the language otherwise has.

Considering the broad cultural reach of WTEWYE, the language present in the text is troubling on many counts. The use of gender norms, constructing risk as the mother's personal responsibility, dehumanizing body-as-machine metaphors, and the promotion of increased medicalization and surveillance of women's bodies by both women themselves and of their practitioners can have far reaching harmful consequences, which could possibly be trickling down and participating in a prevalent culture of violence against women. Thus, there is an obligation to continue critiquing the ways in which language is used to perpetuate the dangerous ideologies critiqued above. This is especially true in cases like WTEWYE, where the broad cultural reach has the potential to influence such a wide audience. The conversational tone of WTEWYE serves as an additional reminder that we must also remain aware of how we ourselves use language when speaking or writing about pregnant women so that we do not fall into the pattern of insidiously reinforcing harmful norms and expectations. 


\section{Works Cited}

Althusser, Louis. "Ideology and Ideological State Apparatuses (Notes Towards an Investigation)" Lenin and Philosophy and Other Essays. Trans Ben Brewster. Monthly Review Press, 1972. Print.

Anderson, Irina and Kathy Doherty. Accounting For Rape: Feminism and Discourse Analysis in the Study of Sexual Violence. New York: Routledge, 2008. Print.

Ayala, Saray, and Lauren Freeman. "The Placental Microbiome: A New Site For Policing Women's Bodies." International Journal of Feminist Approaches to Bioethics. 9.1 (2016): 121-146. Print.

Brauer, Susanne. "Moral Implications of Obstetric Technologies for Pregnancy and Motherhood." Med Health Care and Philosphy, 19 (2016): 45-54. DOI: 10.1007/s11019015-9635-8.

Breger, Melissa L. “Transforming Cultural Norms of Sexual Violence Against Women.” Journal of Research in Gender Studies 4.2 (2014): 39-51. Print.

Campo-Engelstein, Lisa and Nadia L. Johnson. “Revisiting ‘The Fertilization Fairytale:' An Analysis of Gendered Language Used to Describe Fertilization in Science Textbooks From Middle School to Medical School.” Cultural Studies of Science Education 9 (2014): 201220. Print.

Conrad, Peter. The Medicalization of Society: On the Transformation of Human Conditions into Treatable Disorders. Baltimore: Johns Hopkins U P, 2007. Print.

Corea, Gena. "Reproductive Control: The War Against The Womb." The Mother Machine: 
Reproductive Technologies from Artificial Insemination to Artificial Wombs. New York: Harper \& Row, 1985. Print.

Corea, Gena et al. Man-Made Women: How New Reproductive Technologies Affect Women. Bloomington: Indiana U P, 1987. Print.

Cudd, Ann E. Analyzing Oppression. Oxford U P, 2006. Print.

Dobris, Catherine A., and Kim White-Mills. "Rhetorical Visions of Motherhood: A Feminist Analysis Of The What To Expect Series.” Women \& Language 29.1 (2006): 26-36. Print. Duden, Barbara. Disembodying Women: Perspectives on Pregnancy and the Unborn. Cambridge, Mass.: Harvard University Press, 1993. Print.

Eisenburg, Arlene, Heidi Eisenberg Murkoff, and Sandee Eisenberg Hathaway, R.N. What to Expect When You're Expecting. New York: Workman Publishing, 1984. Print.

Eptein, Steven. "Bodily Differences and Collective Identities: The Politics of Gender and Race in Biomedical Research in the United States" Body and Society. 10 (2004): 183203. Print.

Flavin, Jeanne. Our Bodies, Our Crimes: The Policing of Women's Reproduction in America. New York: New York U P, 2009. Print.

Flood, Michael, and Bob Pease. "Factors Influencing Attitudes To Violence Against Women." Trauma, Violence, \& Abuse 10.2 (2009): 125-142. Web. DOI:10.1177/1524838009334131. Frye, Marilyn. "Oppression And The Use Of Definition.” The Politics of Reality. Trumansburg, N.Y.: The Crossings Press, 1983. Print.

Gilman, Sander L. et al. Hysteria Beyond Freud. Berkeley: U of California P, 1993. Print. Gordon, Linda. The Moral Property of Women: A History of Birth Control Politics in America. Chicago: U of Illinois P, 2002. Print. 
Grothues, Carol A. and Shelly L. Marmion. "Dismantling the Myths About Intimate Violence Against Women” Lundberg-Love and Marmion 9-14.

Haslam, Nick. "Dehumanization: An Integrative Review.” Personality and Social Psychology Review 10.3 (2006): 252-264. Web.

Haslanger, Sally. "Critical Theory and Practice: Ideology and Morality” Spinoza Lecture. 21 May 2015, Amsterdam Institute for Humanities Research, Amsterdam

Herrle-Fanning, Jeanette. "Firguring the Reproductive Woman: The Construction of Professional Identity in Eighteenth-Century British Midwifery Texts.” Lay et al 29-48.

Keifer, Amy K. and Denise Sekaquaptewa. “Implicit Stereotypes and Women’s Math Performance: How Implicit Gender-Math Stereotypes Influence Women’s Susceptibility to Stereotype Threat.” Journal of Experimental Social Psychology. 43.5 (2009): 825-832. Print.

Klein, Renate Duelli. "What's 'new' About the 'new' Reproductive Technologies?” Corea et al 64-73.

Kopelson, Karen. “Writing Patient's Wrongs: The Rhetoric and Reality of Information Age Medicine.” JAC. 29.1/2 (2009): 353-404. Print.

Kuhse, Helga and Peter Singer, eds. Bioethics: An Anthology. $2^{\text {nd }}$ ed., Blackwell Publishing Ltd., 2006. Print.

Kukla, Rebecca. "Measuring Mothering” The International Journal of Feminist Approaches to Bioethics. 1.1 (2008): 67-90. Print.

Lay, Mary M., Laura J. Gurak, Clare Gravon, Cynthia Myntti eds. Body Talk: Rhetoric, Technology, Reproduction. Madison: The U of Wisconsin P, 2000. Print. Lock, Margaret. "Situating Women in the Politics of Health.” Sherwin et al. 48-63. 
Lundberg-Love, Paula K., and Shelly L. Marmion, eds. "Initimate” Violence Against Women:

When Spouses, Partners, or Lovers Attack. Westport: Praeger Publishers, 2006. Print.

Lyerly, Anne Drapkin et al. "Risk and the Pregnant Body” Hastings Center Report 39.6 (2009): 34-42. Print.

Marmion, Shelly L. and Donna Lee Faulkner. "Effects of Class and Culture on Intimate Partner Violence.” Lundberg-Love and Marmion 131-144.

Martin, Emily. "The Egg and the Sperm: How Science Has Constructed A Romance Based On Stereotypical Male-Female Roles.” Signs 16.3 (1991): 485-501. Jstor.

Morgan, Kathryn Pauly. “Contested Bodies, Contested Knowledges: Women, Health, and the Politics of Medicalization.” Sherwin et al. 83-121.

Murkoff, Heidi, and Sharon Mazel. What To Expect When You're Expecting: $5^{\text {th }}$ Edition. New York: Workman Publishing, 2016. Print.

Nichols, Brittney. "Violence Against Women: The Extent of the Problem." Lundberg-Love and Marmion 1-8.

Parrot, Andrea and Nina Cummings. Forsaken Females: The Global Brutalization of Women. Lanham: Rowman and Littlefeild Publishers, Inc, 2006. Print.

Petchesky, Rosalind Pollack. "Fetal Images: The Power of Visual Culture in the Politics of Reproduction." Feminist Studies 13.2 (1987): 263-92. Web.

Purdy, Laura M. “Are Pregnant Women Fetal Containers?” Kuhse and Singer 65-75. Print. Rothman, Barbara Katz. Recreating Motherhood. New Brunswick, NJ: Rutgers University Press, 2000. Print.

Rowland, Robyn. Living Laboratories: Women and Reproductive Technologies. Bloominton: Indiana U P, 1992. Print. 
Richardson, Sarah S. et al. “Don't Blame the Mothers.” Nature. 512 (2014): 131-132. Print.

Seigel, Marika. The Rhetoric of Pregnancy. Chicago: The U of Chicago P, 2014. Print.

Shanner, Laura. “Bodies, Minds, and Failures: Images of Women In Infertility Clinics.” Lay et al 142-160.

Sherwin, Susan. “Gender, Race, and Class in the Delivery of Health Care." No Longer Patient: Feminist Ethics and Health Care. Temple U P, 1992. Print.

Sherwin, Susan. "Normalizing Reproductive Technologies and the Implications for Autonomy." Tong et al 96-113.

Sherwin, Susan et al. The Politics of Women's Health: Exploring Agency and Autonomy. Philadelphia: Temple U P, 1998. Print.

Showalter, Elaine. “Hysteria, Feminism, and Gender.” Gilman et al 286-344.

Solinger, Rickie. Pregnancy and Power: A Short History of Reproductive Politics in America. New York: New York U P, 2005. Print.

Tong, Rosemarie, Gwen Anderson, and Aida F. Santos, eds. Globalizing Feminist Bioethics: Crosscultural Perspectives. Boulder: Westview Press, 2001. Print.

Ward, Camille N. and Paula K. Lundberg-Love. "Sexual Abuse of Women.” Lundberg-Love and Marmion 47-68.

Wetterberg, Anna. "My Body, My Choice...My Responsibility: The Pregnant Woman As Caretaker Of The Fetal Self.” Berkeley Journal of Sociology 48 (2004): 26-49. Jstor.

Wolf, Joan B. "Is Breast Really Best?: Risk and Total Motherhood in the Nation Breastfeeding Awareness Campaign.” Journal of Health Politics, Policy and Law. 32.4 (2007): 595-636. Print.

Woliver, Laura R.. The Political Geographies of Pregnancy. Chicago: U of Illinois P, 2002. 
Print.

World Health Organization. "Violence Against Women: Intimate Partner and Sexual Violence Against Women.” WHO.int. 2007. Accessed 12 Dec 2016.

Wright, Peter J. and Robert S. Tokunaga. “Men’s Objectifying Media Consumption, Objectification of Women, and Attitudes Supportive of Violence Against Women." Archives of Sexual Behavior 45.4 (2016): 955-964. DOI:10.1007/s10508-015-0644-8. 